\title{
EFEITO DE Colletotrichum dematiumVAR. Truncata E Cercospora kikuchii NA GERMINAÇÃO DE SEMENTES DE SOJA ${ }^{1}$
}

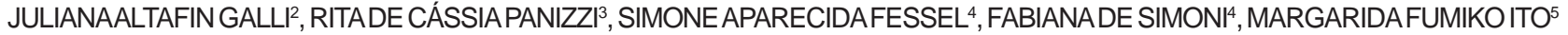

\begin{abstract}
RESUMO - A antracnose, causada por Colletotrichum dematium var. truncata, é a principal doença da soja que afeta a fase inicial de formação das vagens, podendo causar a morte das plântulas. Cercospora kikuchii é o fungo causador da doença mancha púrpura nas sementes de soja, responsável por severas reduções no rendimento e na qualidade das sementes. O objetivo deste trabalho foi determinar o tempo mais apropriado para infecção das sementes de soja por $C$. dematium var. truncata e $C$. kikuchii, para posterior avaliação dos danos causados pelo fungo na germinação. Tais fungos foram cultivados em meio BDA. As sementes de soja cultivar MSOY 6101 foram colocadas sobre meio contendo o patógeno $C$. dematium var. truncata por 0 (testemunha), 4, 16, 24, 32 e 40h. As sementes da cv. CD 208 foram inoculadas com C. kikuchii pelos mesmos períodos citados, com adição de 48 e 56h. Após os respectivos tempos de contato, as sementes foram submetidas ao teste de sanidade (papel de filtro), com duas variações, sem e com assepsia superficial (hipoclorito de sódio 1\% por três minutos). Determinado o tempo mais adequado de infecção, outras sementes foram infectadas pelo patógeno e, posteriormente, foram realizados testes de germinação em papel e areia com uma mistura de sementes sadias (colocadas sobre o meio BDA) e sementes inoculadas, resultando em lotes com 0, 20, 40, 60, 80 e 100\% de sementes infectadas. O tempo de incubação de 40 e 56 horas para $C$. dematium var truncata e $C$. Kikuchii, respectivamente são suficientes para obtenção da totalidade das sementes infectadas. C. Kikuchii não prejudica a germinação das sementes.
\end{abstract}

Termos para indexação: antracnose, mancha púrpura, patologia de sementes.

\section{EFFECT OF COLLETOTRICHUM DEMATIUM VAR. TRUNCATA AND CERCOSPORA KIKUCHII ON SOYBEAN SEED GERMINATION}

\begin{abstract}
Anthracnose, caused by Colletotrichum dematium var. truncata, is the main soybean disease that affects soybean yields. Cercospora kikuchii is the fungus that causes the purple stain disease in soybean seeds that causes severe reductions in the yield and quality of the seeds. The objective of this study was to determine the optimum period of contact of the soybean seeds with $C$. dematium var. truncata and C. kikuchii, for subsequent evaluation of the damage caused by the fungus on seed germination. The fungus was cultivated in PDA medium. The soybean seeds cv. MSOY 6101 were placed on Petri dishes with culture media colonized by C. dematium var. truncata for 0 (control), 4, 16, 24, 32 and 40h. The seeds of the cv. CD 208 were inoculated with C. kikuchii for the same mentioned periods, with the addition of 48 and 56h. After the respective periods of contact, they were submitted to the Blotter test, with and without superficial asepsis (sodium hipoclorite 1\%, 3 minutes). After determining the optimum incubation
\end{abstract}

\footnotetext{
${ }^{1}$ Submetido em 04/03/2004. Aceito para publicação em 27/04/2005.

${ }^{2}$ Aluna de Doutorado do Curso de Produção Vegetal na FCAV/UNESP, Via de Acesso Prof. Dr. Paulo D. Castellane, s/n, CEP: 14884-900, Jaboticabal/ SP.julianagalli@zipmail.com.br
}

\footnotetext{
${ }^{3}$ Profa. Departamento de Fitossanidade, FCAV/UNESP.

${ }^{4}$ Alunas de Doutorado do Curso de Produção e Tecnologia de Sementes na FCAV/UNESP.

${ }^{5}$ Pesquisadora IAC - Campinas.
} 
period, other seeds were infected with the pathogen and, later, germination tests were accomplished in paper and in sand with a mixture of healthy seeds (placed on PDA medium) and inoculated seeds, resulting in lots with 0, 20, 40, 60, 80 and 100\% infected seeds. The incubation time of $C$. dematium var truncata and C. Kikuchii, was 40 and 56 hours, respectively, and was sufficient to obtain completely infected seeds. C. Kikuchii not reduce seed germination.

Index terms: anthracnose, stain purple, seed pathology.

\section{INTRODUÇÃO}

A maior parte dos fungos patogênicos associados à soja tem as sementes como principal veículo de introdução em novas áreas de plantio, causando sérios danos a cultura sob condições ambientais ao desenvolvimento do patógeno (França Neto e Henning, 1984). Ito e Tanaka (1993) afirmam que além desses aspectos citados, a presença de certos patógenos nas sementes pode resultar em efeitos diretos, como a redução do potencial germinativo, do vigor, da emergência, do período de armazenamento e até do rendimento.

Os principais patógenos transmitidos pela semente de soja são: Cercospora kikuchii, Cercospora sojina, Fusarium semisectum, Phomopsis spp., anamorfo de Diaporthe spp. e Colletotrichum truncatum (Embrapa, 2002).

A antracnose (Colletotrichum dematium var. truncata), sob condições de alta umidade, causa apodrecimento e queda das vagens, abertura das vagens imaturas e germinação dos grãos em formação. Pode ocasionar perda total da produção, mas com maior freqüência, causa alta redução do número de vagens e induz a planta à retenção foliar e haste verde (Embrapa, 2002).

Cercospora kikuchii causa mancha púrpura em sementes de soja e penetra no tegumento da semente pelo funículo (Sinclair e Backman, 1989). O patógeno ataca todas as partes da planta e pode ser responsável por severas reduções no rendimento e na qualidade da semente (Almeida et al., 1997).

A inoculação artificial de sementes de soja com $C$. dematium var. truncata e C. kikuchii pode ser útil na verificação da localização do patógeno nas sementes, na determinação do seu efeito sobre a qualidade fisiológica destas e no preparo de amostras com incidências conhecidas do patógeno. Segundo Tanaka et al. (1989), um método de inoculação de patógenos nas sementes que proporcione a associação do tipo de infecção e não limite a semeadura imediatamente após a inoculação é de grande utilidade.

Utilizando a técnica de restrição hídrica para a inoculação de sementes de soja com os fungos $C$. dematium var. truncata, Phomopsis sojae e Sclerotinia sclerotiorum, Machado et al.
(2001). verificaram que a inoculação das sementes nos potenciais hídricos mais elevados proporcionou os maiores índices de plantas doentes sem afetar negativamente a germinação das sementes. Os autores também relataram que para fungos muito agressivos como C. dematiuum var. truncata não há a necessidade de prolongamento do tempo de exposição das sementes ao inóculo, visto que no menor tempo utilizado, de 48 horas, obteve-se quase $100 \%$ de infecção.

Avaliando a qualidade fisiológica e sanitária de sementes de genótipos de soja do ciclo precoce/médio, Hamawaki et al. (2002) verificaram que a germinação das sementes correlacionou-se positivamente com o vigor das sementes e negativamente com a incidência de Fusarium semisectum, Phomopsis sojae e Colletotrichum dematium, indicando o efeito desfavorável desses patógenos na germinação das mesmas. Dos patógenos avaliados, o genótipo CSP-2 apresentou maior incidência de C. dematium (3,84\%) e, conseqüentemente, vigor significativamente menor (68,5\%) do que o vigor das sementes dos genótipos UVF 94-426803 e FT-2001, que apresentaram 0\% de infecção pelo patógeno (89,5\% e 85,5\%, respectivamente).

Em experimento semelhante, Bringel et al. (2001) verificaram que das nove cultivares de soja testadas, a cultivar BRSMA Juçara apresentou as maiores porcentagens de incidência dos fungos Cercospora kikuchii e Fusarium spp. (26\% e $42 \%$, respectivamente) e a menor porcentagem de germinação (40\%) em comparação com os demais cultivares testados.

O exame visual das sementes de soja não é suficiente para determinar a real porcentagem de incidência de sementes infectadas com C. kikuchii, e que a presença deste fungo tende a reduzir a germinação e o vigor das sementes (Lucca Filho e Casela, 1983).

Existem dados conflitantes na literatura com relação ao efeito de Cercospora kikuchii sobre a qualidade fisiológica das sementes (Roy e Abney, 1976, 1977). Reis e Goulart (1998) demonstraram não haver efeito negativo desse fungo na qualidade fisiológica de sementes de soja. 
Dada à relativa importância do assunto, os objetivos deste trabalho foram determinar o tempo mais adequado para infecção das sementes de soja por Cercospora kikuchii e Colletotrichum dematium var. truncata e o efeito dos patógenos na germinação das mesmas.

\section{MATERIALE MÉTODOS}

O experimento foi realizado no Laboratório de Patologia de Sementes, do Departamento de Fitossanidade e no Laboratório de Análise de Sementes, do Departamento de Produção Vegetal da Faculdade de Ciências Agrárias e Veterinárias da UNESP, Jaboticabal - SP.

Os isolados de C. dematium var. truncata e C. kikuchii usados nos experimentos fazem parte da micoteca do Instituto Agronômico de Campinas (IAC) e foram obtidos a partir de sementes e hastes de plantas de soja com sintomas típicos de antracnose e mancha púrpura. Para o isolamento, sementes e fragmentos de tecidos de hastes doentes sofreram desinfestação superficial, que consistiu na imersão destes em álcool por 30 segundos e, em seguida, em solução de hipoclorito de sódio 1\% por um minuto. Após a desinfestação superficial, os materiais foram transferidos para placas de Petri contendo o meio de cultura BDA e incubados à temperatura ambiente. Após duas semanas, os fungos foram repicados para tubos de ensaio contendo BDA, onde se desenvolveram em cultura pura e, para conservação, foram cobertos com uma camada de óleo Nujol estéril. Para a obtenção do inóculo, os isolados conservados em óleo foram repicados para placas de Petri contendo meio BDA e mantidos à temperatura ambiente por quinze dias.

As sementes de soja utilizadas neste experimento foram da cultivar MSOY 6101, para a inoculação com $C$. dematium var. truncata, e CD 208, para a inoculação com $C$. kikuchii. As sementes de soja foram previamente desinfestadas com hipoclorito de sódio a $1 \%$ por três minutos. Após a secagem, sobre folhas de papel de filtro esterilizadas, procedeuse à inoculação, que consistiu na deposição das sementes em placas contendo o inóculo. As sementes permaneceram em contato com o patógeno por zero (testemunha), 4, 16, 2432 e 40 horas. Para o experimento com C. kikuchii, foram adicionados mais dois períodos de contato, 48 e 56 horas.

Após os respectivos períodos de incubação, as sementes foram submetidas ao teste de sanidade (papel de filtro), sem e com assepsia superficial (hipoclorito de sódio a 1\% por três minutos). Foram colocadas 10 sementes por placa, totalizando 100 sementes por tratamento, colocadas sobre três folhas de papel de filtro previamente umedecidas com água destilada. A incubação realizou-se à temperatura de $20 \pm 2^{\circ} \mathrm{C}$ e fotoperíodo de 12 horas sob luz branca fluorescente, e as sementes foram examinadas sob microscópio estereoscópio para a detecção dos patógenos após sete dias.

$\mathrm{Na}$ análise estatística utilizou-se o delineamento inteiramente casualizado e os dados foram submetidos à análise de variância pelo teste $\mathrm{F}$, utilizando-se o esquema fatorial $5 \times 2$ e $7 \times 2$, para os experimentos com $C$. dematium var. truncata e C. kikuchii, respectivamente (período de contato das sementes x sem e com desinfestação prévia).

Determinado o período de incubação mais adequado (onde as sementes apresentam o patógeno em seu interior), outras sementes foram inoculadas por contato sobre o meio de cultura colonizado, conforme descrição anterior e, posteriormente, dispostas sobre placas contendo papel de filtro esterilizado, para secagem. O experimento constou de seis tratamentos com quatro repetições de 50 sementes, totalizando 200 sementes por tratamento. Os tratamentos constaram de uma mistura de sementes sadias com sementes inoculadas com Colletotrichum dematium var. truncata e Cerospora kikuchii, resultando em lotes de sementes com 20, 40, 60, 80 e 100\% de infecção, e uma testemunha com sementes provenientes do plaqueamento sobre o meio de cultura sem o fungo, durante o mesmo período de tempo necessário para a inoculação dos patógenos.

O teste de germinação foi realizado, de acordo com as Regras para Análise de Sementes (Brasil, 1992), em rolo de papel umedecido com um volume de água equivalente a 2,5 vezes o seu peso, e em areia, mantidos a $25^{\circ} \mathrm{C}$, efetuou-se a avaliação oito dias após a montagem para lotes com diferentes porcentagens de sementes contaminadas por Colletotrichum dematium var. truncata e Cercospora kikuchii. O delineamento experimental utilizado foi inteiramente casualizado e os dados submetidos à análise de variância pelo teste $\mathrm{F}$, utilizando esquema fatorial 6x2 (porcentagens de infecção x germinação em rolo de papel e areia).

\section{RESULTADOS E DISCUSSÃO}

Pela Tabela 1, verificou-se que todos os períodos de contato das sementes com o patógeno foram suficientes para sua contaminação, mas somente o período de 40 horas conseguiu a totalidade das sementes com o patógeno em seu interior, comprovado pela prévia desinfestação superficial das mesmas com hipoclorito de sódio.

Patógenos associados às sementes são transportados de 
TABELA1. Efeito do período de incubação das sementes de soja cv. MSOY 6101 na infeç̧ão destas por Colletotrichum dematium var. truncata.

\begin{tabular}{ccrrr}
\hline \multirow{2}{*}{$\begin{array}{c}\text { Período de incubação } \\
\text { (horas) }\end{array}$} & \multicolumn{4}{c}{ Fungos (\%) } \\
\cline { 2 - 5 } & $\begin{array}{c}\text { Sem desinfestação } \\
\text { prévia }\end{array}$ & \multicolumn{2}{c}{$\begin{array}{c}\text { Com desinfestação } \\
\text { prévia }\end{array}$} \\
\hline 4 & $17,53 \mathrm{Aa}$ & $9^{1,2}$ & $4,65 \mathrm{Bd}$ & 2 \\
16 & $18,52 \mathrm{Aa}$ & 96 & $8,83 \mathrm{Bc}$ & 20 \\
24 & $18,81 \mathrm{Aa}$ & 99 & $12,55 \mathrm{Bb}$ & 43 \\
32 & $18,91 \mathrm{Aa}$ & 100 & $16,72 \mathrm{Ba}$ & 78 \\
40 & $18,91 \mathrm{Aa}$ & 100 & $18,52 \mathrm{Aa}$ & 96 \\
\hline C.V.(\%) & & & 10,3888 & \\
\hline
\end{tabular}

${ }^{1}$ Médias seguidas pela mesma letra, maiúscula na linha e minúscula na coluna, não diferem entre si, pelo teste de Tukey, a 5\%;

2 Dados trasformados em arco seno $(\mathrm{x} / 100)^{1 / 2}$;

${ }^{3}$ Valores originais em \%;

duas maneiras: infecção ou infestação (contaminação). A infecção implica que o patógeno é transportado internamente, incrustrado nos tecidos da semente. Quando um patógeno é transportado passivamente, ele é um contaminante ou infestante. Neste caso, o patógeno localiza-se sobre a superfície da semente (Agarwal e Sinclair, 1987).

Sementes colonizadas por Colletotrichum dematium var. truncata apresentam áreas com manchas marrons escuras e enrugadas, apesar do fungo poder infectar as sementes sem causar sintomas (Sinclair e Backman, 1989). Estudos histopatológicos sobre sementes de soja infectadas por $C$. truncatum mostram que este fungo usualmente coloniza o tegumento da semente, formando acérvulos, mas raramente os tecidos do embrião (Schneider et al., 1974; RodriguezMarcano e Sinclair, 1978).

Inoculando sementes de algodão com Colletotrichum gossypii var. cephalosporioides, Tanaka et al. (1989) observaram que o contato das sementes com o inóculo, a partir de 12 até 48 horas, resultou em associação tipo infecção, decorrente da penetração do fungo pelo tegumento. Os autores elegeram como ideal o período de 24 horas de exposição ao patógeno, ressaltando que em períodos menores corre-se o risco de não haver penetração em nível satisfatório e, em períodos superiores, a semente pode absorver água em quantidade suficiente para levar a um comprometimento da germinação. Esses autores ainda afirmam que uma vantagem desse método de inoculação das sementes por contato é proporcionar a obtenção de sementes infectadas de maneira bastante semelhante a que ocorre naturalmente, e em níveis desejados e pré-estabelecidos.

Em relação a Cercospora kikuchii (Tabela 2), para o tratamento sem desinfestação, todos os períodos de contato das sementes com o patógeno foram suficientes para sua
TABELA2. Efeito do período de incubação das sementes de soja cv. CD 208 na infecção destas por Cercospora kikuchii.

\begin{tabular}{cccccr}
\hline \multirow{2}{*}{$\begin{array}{c}\text { Período de incubação } \\
\text { (horas) }\end{array}$} & \multicolumn{5}{c}{ Fungos (\%) } \\
\cline { 2 - 6 } & $\begin{array}{c}\text { Sem desinfestação } \\
\text { prévia }\end{array}$ & $\begin{array}{c}\text { Com desinfestação } \\
\text { prévia }\end{array}$ \\
\hline 4 & $18,81^{1,2}$ & Aa & $99^{3}$ & $4,65 \mathrm{Bd}$ & 2 \\
16 & 18,71 & Aa & 98 & $6,71 \mathrm{Bd}$ & 11 \\
24 & 18,91 & Aa & 100 & $9,39 \mathrm{Bc}$ & 24 \\
32 & 18,91 & Aa & 100 & $10,98 \mathrm{Bc}$ & 33 \\
40 & 18,91 & Aa & 100 & $14,55 \mathrm{Bb}$ & 59 \\
48 & 18,91 & Aa & 100 & $14,04 \mathrm{Bb}$ & 55 \\
56 & 18,91 & Aa & 100 & $18,03 \mathrm{Aa}$ & 91 \\
\hline C.V. (\%) & & & & 10,6534 &
\end{tabular}

${ }^{1}$ Médias seguidas pela mesma letra, maiúscula na linha e minúscula na coluna, não diferem entre si, pelo teste de Tukey, a 5\%;

${ }^{2}$ Dados transformados em arco seno $(\mathrm{x} / 100)^{1 / 2}$;

${ }^{3}$ Dados originais em \%;

contaminação, mas apenas o período de 56 horas foi suficiente para a totalidade de sementes com o patógeno em seu interior.

Para Colletotrichum dematium var. truncata em relação à germinação (Tabela 3), não houve diferença significativa entre os métodos de germinação empregados, rolo de papel e areia. Quanto aos tratamentos de infecção de sementes, lotes de sementes com $20 \%$ de infecção não diferiram significativamente da testemunha (sem infecção), mas diferiram dos demais tratamentos. Não houve diferença significativa entre o tratamento com 40 e $60 \%$ de sementes infectadas, apesar desse último ter apresentado valores menores. De modo geral, obteve-se uma correlação inversamente proporcional entre germinação de sementes e sementes infectadas, sendo que quanto maior a porcentagem de sementes infectadas, menor a germinação das mesmas. Esses resultados estão de acordo com os encontrados por Hamawaki et al. (2002).

TABELA3. Efeito de diferentes níveis de infecção de sementes de soja por Colletotrichum dematium var. truncata sobre a germinação.

\begin{tabular}{|c|c|c|c|c|c|}
\hline \multirow{3}{*}{$\begin{array}{c}\text { \% Sementes } \\
\text { infectadas }\end{array}$} & \multicolumn{5}{|c|}{ Germinação (\%) } \\
\hline & \multicolumn{2}{|c|}{ Papel } & \multicolumn{2}{|c|}{ Areia } & média \\
\hline & $71,19^{1}$ & $89^{2}$ & 71,21 & 89 & $71,20^{3} \mathrm{a}$ \\
\hline 20 & 68,61 & 86 & 67,82 & 85 & $68,22 \quad a$ \\
\hline 40 & 60,41 & 75 & 60,20 & 75 & 60,30 \\
\hline 60 & 58,09 & 72 & 53,47 & 64 & 55,78 \\
\hline 80 & 49,61 & 58 & 50,19 & 59 & 49,90 \\
\hline 100 & 45,00 & 50 & 44,14 & 48 & 44,57 \\
\hline média & 58 & $2 \mathrm{~A}$ & 57 , & $4 \mathrm{~A}$ & \\
\hline C.V. (\%) & & & & 649 & \\
\hline
\end{tabular}

${ }^{1}$ Dados transformados em arco seno $(\mathrm{x} / 100)^{1 / 2}$;

${ }^{2}$ Dados originais em \%;

${ }^{3}$ Médias seguidas pela mesma letra, maiúscula na linha e minúscula na coluna, não diferem entre si, pelo teste de Tukey, a 5\%; 
Apesar dos testes de germinação em rolo de papel e areia não terem diferido significativamente entre si, Bizetto e Homechin (1997), avaliando a germinação de sementes de soja com altos índices de Phomopsis sojae, verificaram que para emergência em areia, o número de plântulas normais foi superior ao do teste padrão de germinação no laboratório. Henning e França Neto (1980) também relataram a superioridade do teste de emergência com o emprego de solo ou areia como substrato em relação aos porcentuais de germinação obtidos no teste de germinação. Segundo França Neto e Henning (1984), este fato, provavelmente, é devido ao mecanismo de escape, no qual a plântula ao emergir libera o tegumento infectado no solo, enquanto que no teste de germinação (rolo de papel), o tegumento e o patógeno a ele aderido permanecem aderidos aos cotilédones, causando a deterioração das sementes.

Na Tabela 4 são apresentados os resultados do efeito dos diferentes níveis de infecção de sementes de soja por Cercospora kikuchii sobre a germinação. Não houve diferença significativa entre os testes de germinação realizados, rolo de papel e areia. Quanto aos níveis de infecção, estes também não diferiram significativamente entre si. O padrão mínimo de qualidade para sementes de soja fiscalizadas no estado de São Paulo é de 80\% de germinação (Embrapa, 2002). Partindo desse valor, pode-se dizer que a maioria dos tratamentos testados atingiu esse patamar, com exceção do teste de germinação em rolo de papel em níveis de infecção de 40 e $60 \%$ (75 e $72 \%$ de germinação, respectivamente) e do teste de germinação em areia a 40\% de infecção (79\% de germinação). Resultados semelhantes foram relatados por Reis e Goulart (1998).

Avaliando a degradação seletiva de proteínas por $C$. kikuchii e Phomopsis longicolla no tegumento e cotilédones

TABELA 4. Efeito de diferentes níveis de infecção de sementes de soja por Cercospora kikuchii sobre a germinação.

\begin{tabular}{|c|c|c|c|c|c|}
\hline \multirow{3}{*}{$\begin{array}{c}\text { \% Sementes } \\
\text { infectadas } \\
0\end{array}$} & \multicolumn{5}{|c|}{ Germinação (\%) } \\
\hline & \multicolumn{2}{|c|}{ Papel } & \multicolumn{2}{|c|}{ Areia } & média \\
\hline & $66,77^{1}$ & $84^{2}$ & 70,24 & 88 & $68,51^{3} \mathrm{ab}$ \\
\hline 20 & 68,08 & 86 & 69,60 & 87 & $68,84 \mathrm{ab}$ \\
\hline 40 & 63,50 & 75 & 63,33 & 79 & 63,41 \\
\hline 60 & 61,71 & 72 & 64,21 & 81 & 62,96 \\
\hline 80 & 70,87 & 89 & 68,20 & 85 & 69,53 \\
\hline 100 & 68,21 & 86 & 68,14 & 86 & 68,18 \\
\hline média & $66,52 \mathrm{~A}$ & & & & \\
\hline C.V. $(\%)$ & \multicolumn{5}{|c|}{6,2640} \\
\hline
\end{tabular}

de sementes de soja, Velicheti et al. (1992) relataram que, para C. kikuchii, todas as sementes infectadas germinaram, similarmente às sementes sem sintomas. Foi constatada a degradação das proteínas do tegumento das sementes infectadas, mas não foi observada a degradação de proteínas cotiledonares. Afirmam ainda que a germinação e a sobrevivência de sementes de soja, infectadas por $C$. kikuchii, foram mantidas por mais de 30 dias sob condições de luz, sugerindo que o fungo ou sua toxina, cercosporin, tiveram um efeito insignificante na germinação de sementes ou mortalidade de plântulas. Estudando a transmissibilidade e os danos causados por Cercospora kikuchii em sementes de soja, Oliveira et al. (1993) verificaram que, através de testes de germinação e pelo exame visual das plântulas, C. kikuchii não afetou o desempenho das sementes até o estágio de plântula, mesmo quando as sementes apresentaram alta porcentagem de incidência do patógeno (94\%).

\section{CONCLUSÕES}

O tempo de incubação de 40 e 56 horas para $C$. dematium var truncata e C. Kikuchii, respectivamente, são suficientes para obtenção da totalidade das sementes infectadas.

C. Kikuchii não prejudica a germinação das sementes.

\section{REFERÊNCIAS}

AGARWAL, V. K.; SINCLAIR, J.B. Principles of seed pathology. Boca Raton: CRC Press, 1987. v.1, 175p.

ALMEIDA, A.M.R.; FERREIRA, L.P.; YORINORI, J.T.; SILVA, J.F.V.; HENNING, A.A. Doenças da soja. In: KIMATI, H.; AMORIM, L.; BERGAMIN FILHO, A.; CAMARGO, L.E.A.; REZENDE, J.A.M. Manual de Fitopatologia v. 2: Doenças das plantas cultivadas. 3 ed. São Paulo: Agronômica Ceres, 1997. p. 642-664.

BIZETTO, A.; HOMECHIN, M. Efeito do período e da temperatura de armazenamento na qualidade fisiológica e sanitária de sementes de soja com altos índices de Phomopsis sojae (Leh.). Revista Brasileira de Sementes, Brasília, v.19, n.2, p. 196 - 303, 1997.

BRASIL. Ministério da Agricultura e Reforma Agrária. Regras para análise de sementes. Brasília: SNDA/DNDV/CLAV, 1992. 365p.

BRINGEL, J.M.M.; MORAES, M.H.D.; MENTEN., J.O.M.; BEDENDO, I.P. Qualidade sanitária e fisiológica de sementes de soja produzidas na Região de Balsa, Maranhão. Summa Phytopathologica, Jaboticabal, v.27, n.4, p. 438 - 441, 2001.

EMPRESA BRASILEIRA DE PESQUISA AGROPECUÁRIA. Centro Nacional de Pesquisa de Soja. Tecnologias de produção 
de soja. Paraná 2003. Londrina, 2002. 195p.

FRANÇA NETO, J.B.; HENNING, A.A. Qualidade fisiológica e sanitária de sementes de soja. Londrina: Embrapa CNPSo, 1984. n.9, 39p.

HAMAWAKI, O.T.; JULIATTI, F.C.; GOMES, G.M.; RODRIGUES, F.A.; SANTOS, V.L.M. Avaliação da qualidade fisiológica e sanitária de sementes de genótipos de soja do ciclo precoce/ médio em Uberlândia, Minas Gerais. Fitopatologia Brasileira, Brasília, v.27, n.2, p. 201 - 205, 2002.

HENNING, A.A.; FRANÇA NETO, J.B. Problemas na avaliação de germinação de sementes de soja com alta incidência de Phomopsis spp. Revista Brasileira de Sementes, Brasília, v. 2, n. 3, p. 9 - 22, 1980.

ITO, M.F.; TANAKA, M.A.S. Soja - principais doenças causadas por fungos, bactérias e nematóides. Campinas: Fundação Cargill, 1993. p. $1-2$.

LUCCA FILHO, O.A.; CASELA, C.R. Avaliação dos efeitos da mancha púrpura (Cercospora kikuchii) em soja. In: CONGRESSO BRASILEIRO DE SEMENTES, 3., 1983 Campinas. Resumos... Brasília: ABRATES, 1983. p.75.

MACHADO, J.C.; OLIVEIRA, J.A; VIEIRA, M.G.G.C.; ALVES, M.C. Inoculação artificial de sementes de soja por fungos, utilizando solução de manitol. Revista Brasileira de Sementes, Brasília, v.23, n.2, p.95-101, 2001.

OLIVEIRA, J.A.; MACHADO, J.C.; VIEIRA, M.G.G.C.; BRANDÃO JÚNIOR, D.S. Transmissibilidade e danos causados por Cercospora kikuchii em sementes de soja. Revista Brasileira de Sementes, Brasília, v. 15, n.1, p. 97 - 100, 1993.
REIS, H.F.; GOULART, A.C.P. Associação de Cercospora kikuchii com sementes de soja com “mancha púrpura”. Fitopatologia Brasileira, Brasília, v.23, p. 274, 1998. Suplemento.

RODRIGUEZ - MARCANO, A.; SINCLAIR, J.B. Fruiting structures of Colletotrichum dematium var. truncata and Phomopsis sojae formed in soybean seeds. Plant Disease Reporter, Saint Paul, v.62, p. 873-876, 1978.

ROY, K.W.; ABNEY, T.S. Antagonism between Cercspora kikuchii and other seedborne fungi of soybeans. Phytopathology, Saint Paul, v.67, p. 1062 - 1066, 1977.

ROY, K.W.; ABNEY, T.S. Purple seed stain of soybeans. Phytopathology, Saint Paul, v.66, p. 1045-1049, 1976.

SCHNEIDER, R.W.; DHINGRA, D.D.; NICHOLSON, J.F.; SINCLAIR, J.B. Colletotrichum truncatum borne within the seed coat of soybean. Phytopathology, Saint Paul, v. 64, p. 154 - 155, 1974.

SINCLAIR, J.B.; BACKMAN, P.A. Compendium of soybean diseases. 3 ed. Saint Paul: The American Phytopathology Society, 1989. 106p.

TANAKA, M.A.S.; MENTEN. J.O.M.; MARIANNO, M.I.A.; Inoculação artificial de sementes de algodão com Colletotrichum gossypii var. cephalosporioides e infecção das sementes em função do tempo de exposição ao patógeno. Summa Phytopathologica, Jaguariúna, v.15, n.2, p. 232 - 237, 1989.

VELICHETI, R.K.; KOLLIPARA, K.P.; SINCLAIR, J.B. Selective degradation of proteins by Cercospora kikuchii and Phomopsis longicolla in soybean seed coats and cotyledons. Plant Disease, Saint Paul, v. 76, n. 8, p. 779 - 782, 1992. 